\title{
Investigations and Application of Vase Shaping Technology in Acer Elegantulum
}

\author{
Zhiyong Zhu', Li Lin², Lejin Lin $^{3}$ and Guangyuan Cui ${ }^{4}$ \\ Ningbo City College of Vocational Technology
}

\section{Keywords: Acer elegantulum; Plant modeling; Technology}

\begin{abstract}
Acer elegantulum grows fast and is convenient for seed propagation. In this study, we used 2-3 years old Acer elegantulum as the basal plant material to make diverse shapes of vase, stylet and hedge. Later, some high ornamental value maples, including Acer palmatum cv. Dissectum, Nagareizumi and red maple were grafted into the vase, stylet and hedge to make higher ornamental value products. This technology strongly improved the economic value of maples.

Plant model use the plant as raw material, with design by means of the group modeling, created with the characteristics of the plant and for environmental requirements, melting gardening, aesthetics, sculpture etc. as one of the artistic image form ${ }^{[1]}$. The Acer elegantulum is commonly known as a specie of Qingfeng, and is often used as the grafting root stock of Acer palmatum cv. Dissectum and red maple. Because of its less ornamental value when compared with Acer palmatum and its ornamental varieties, the market price of Acer elegantulum is low. Then using Acer palmatum as plant materials, employing of vase, screens and other art forms, grafting the ornamental species of the feather maple, red maple, Nagareizumi, Acer palmatum aureum and other horticultural varieties, producing different patterns of plant modeling work, is an effective technique to improve the ornamental value and economic benefit of the Acer elegantulum.
\end{abstract}

\section{The Breeding of Acer Elegantulum Seedlings}

Standard of Acer Elegantulum for Moulding. The Acer elegantulum which is used to modeled is different from the one that used as rootstock. According to the vase's shape, nursery stock specifications should follow three basic requirements: trunk is straight; taper is small, relatively uniform thickness; with a certain height, generally more than $2 \mathrm{~m}$.

Growth of Acer elegantulum seedlings for moulding

Seeds sawing and breeding

Collecting the fruit when the Acer elegantulum's fruits change from red to brown in the late October to November. After drying the fruit, remove the fruit wings, fruit stalk and impurities and empty seeds by gently rubbing. Placed the mature seeds in ventilated shade or stored in the clean Kawasa Sadumihide before the next growing season.

Use the plastic greenhouse as the nursery to plant seeds, and sowing the seeds in next year from January to February. Then transfer the seedlings to the outdoor in late February to March. Strewing and drilling is available for seeds sowing, and the sowing rate is about $12 \sim 15 \mathrm{~g} / \mathrm{m}^{-2}$. After sowing, covering $1 \mathrm{~cm}$ fine soil to cover the seeds, and it should be covered with $2 \sim 3 \mathrm{~cm}$ straw before sprinkle profoundly water. After these steps, providing enough water for their growth.

The control of seedling density

About 20-25d after the cotyledon emerging, we should regularly check the growth situation of Acer elegantulum and remove the straw. Modeling Acer elegantulum seedlings' cultivation should maintain a higher planting density to get the slender seedlings. In the strewing and drilling ground where the seedling density is too low can be filled through the seedling transplanting, and where dense point is too high can be adjusted by removing some plants. The proper seedling density usually keeped at $15 \mathrm{~cm}$ x $20 \mathrm{~cm}$ of row spacing. The seedlings can be transplanted in late April to mid May, when their height reach $6 \mathrm{~cm} \sim 8 \mathrm{~cm}$ and have totally $4 \sim 6$ true leaves in accordance with the established plant spacing to achieve Acer elegantulum seedling cultivation.

Acer elegantulum seedling need 2 to 3 years growth before use. Strengthen management of soil humidity, drainage, removal of weeds, foliar fertilization, pest control, daily management can 
promote and safeguard of seedling healthy growth.

\section{Vase Shaping of Acer Elegantulum}

Vase Shape Design. Vase shaped design should according to the three principle of appearance beautiful, suitable and operable. Fully excavating and drawing lessons from the essence of Chinese ancient porcelain, painting and other art of vase shape, selected to fit the Acer elegantulum plant biology characteristics of the vase. Vase structure have to be taken into account feasibility of the actual operation of the modeling, the artistic beauty of the vase and the organic combination, by drawing or computer aided design a Acer elegantulum design drawings, to mark the different concave and convex curve parts of the spacing and diameter size (Fig. 1), for use in field Acer elegantulum molding production.
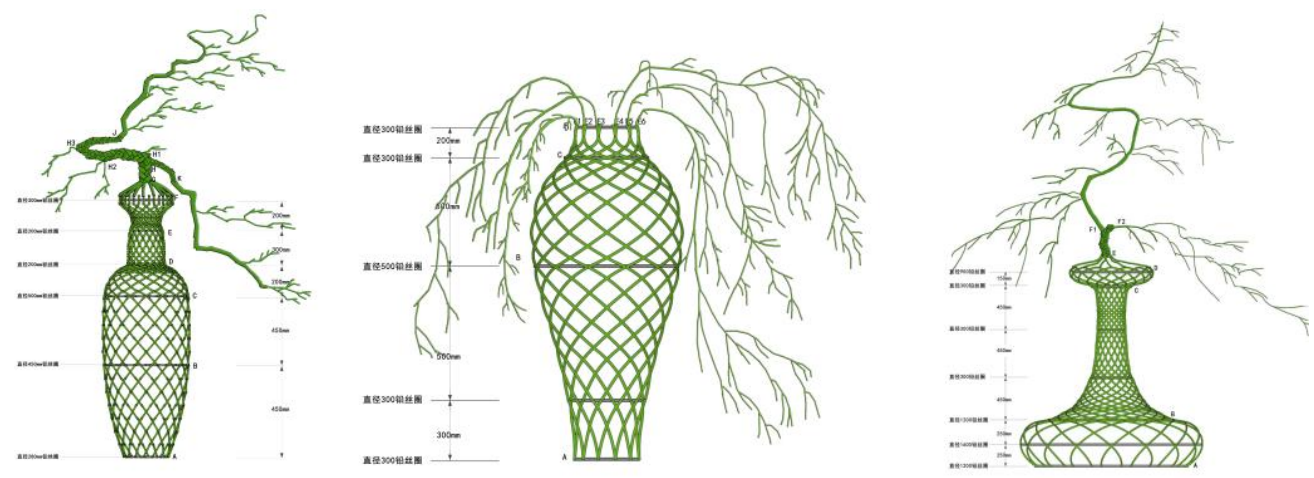

Figure 1. the Acer elegantulummaple vase shape CAD drawing

Seedling Selection. Seedlings are selected according to the organization of vase shapes, and the seedling quality standards is higher in modeling. Keep the similar height and thickness of seedlings in the same vase to the best extent. Too rough weaving operation is difficult, too fine texture is difficult to render the vase. General 2 or 3 years old seedlings selection diameter about $2 \mathrm{~cm}$, height about $2.5 \mathrm{~m}$ Acer elegantulum seedlings, number according to design vases of different sizes.

The Growth of Seedlings. Growth season

Planting before Acer elegantulum buds sprout in early spring, because this time the climate is suitable, the underground root is still growth, recovery growth easily. After planting we should model the Acer elegantulum vase immediately. But the short cut is that the shaped vase with plant death and affects the whole appearance of the vase. If not modeling immediately after planting, we can model them in autumn or early spring, when Acer elegantulum plants survived. If plants did not survive then we can model them after supplement new plants.

Breeding Technology. First, micro terrain processing the pre planting point to make the soil around $20 \sim 50 \mathrm{~cm}$ higher than the ground to avoid flooding after the completion seedlings; Secondly, according to the vase shape's design, circling planting in the block where plant the seedlings and dividing the circle with equal arc length according to plant number to clear each plant distance line designated. Finally, according to the layout planning point to plant Acer elegantulum, and remove pest branches and dry branches.

The Method of Vase Weaving. Vase shaped frame structure is relatively simple type, bottle vase different size changes can be made of some fixed skeleton, skeleton production to the size of the note icon design as the basis. With the aid of the skeleton restyling fabrication process of prepared by weaving, finishing the Acer elegantulum vase shape gradually.

Preparation of Shaping Materials. Skeleton material can be made of the steel material, bamboo, wood and so on. According to practical experience, bamboo is better for its low cost and can reduce high temperature steel burn the branches in summer, it is also convenient to remove. Also can choose the flexible cane plants, bending into ring. When need to erect fixed, we can use appropriate bamboo and stakes. Binding material can choose brown silk, plastic strap, 8 or 10 wire. 
The method of vase weaving

The vase weaving from bottom to top, the first starting from the bottom, gradually to make. In the woven molding process comprehensive use of tied bar, torsion, kneading, pulling, cutting, thinning and other techniques.

The first step is to make the vase base. In accordance with the vase design at the bottom of the annotation designated size lofting planting Acer elegantulum inner placed pre prepared skeleton ring (rims, bamboo circle, etc.), an half of the plants (spaced every tree) according to counter clockwise direction tilt to fix with the skeleton ring, the other half plant (every tree) by clockwise inclination and fixed with skeleton ring, and fixed point in two batches of seedlings did cross point. Lashings available monofilament, plastic strap, 8 or 10 wire etc. All of these make up the vase's base.

The second step, woven the vase bottle. In the vase base, two workers with each other to bottom-up knitting vase bottle, seedling dry intertwined, one by one the size of a diamond grid formation, until the bottle sealed knot so far. All seedling interleaving point is available to use monofilament, plastic buckle belt lashing fixed, in order to facilitate the subsequent rapid healing. According to the design requirements, placing the skeleton ring of an important node in the bottle size change, curvy fixation and protection of the bottle has smooth. During the weaving process, the grid branches have mutual alignment, avoid fluctuated, in order to ensure the orderly and beautiful vase shape grid. For redundant branches can directly influence the vase knitting mesh in comb. The seedling interleaving point can also be used to cut technology, promote their faster healing. But because the cross node number, breaking injury consumes a lot of time.

The third step, the bottleneck and the overall treatment. According to the requirements of the design the size of the vase, placed fixed coil skeleton and tied the Acer elegantulum seedlings top branches lashing fixed on the neck of the bottle frame ring, not amputated seedlings slightly department, to wait Acer elegantulum growth. For different species of maples ornamental varieties of grafted leaving room for choice, for the bottle mouth continued modeling art form left a larger design space.After bottle mouth colligation treatment, the whole vase, use pruning shears on the trunk and slightly branches pruning, the ring skeleton fine-tuning, lashings of long finish. Finally formed Acer elegantulum vase whose vase is chiseled, bottle fluent is curve, grid lines is clear and line edge is smooth (Fig. 2)

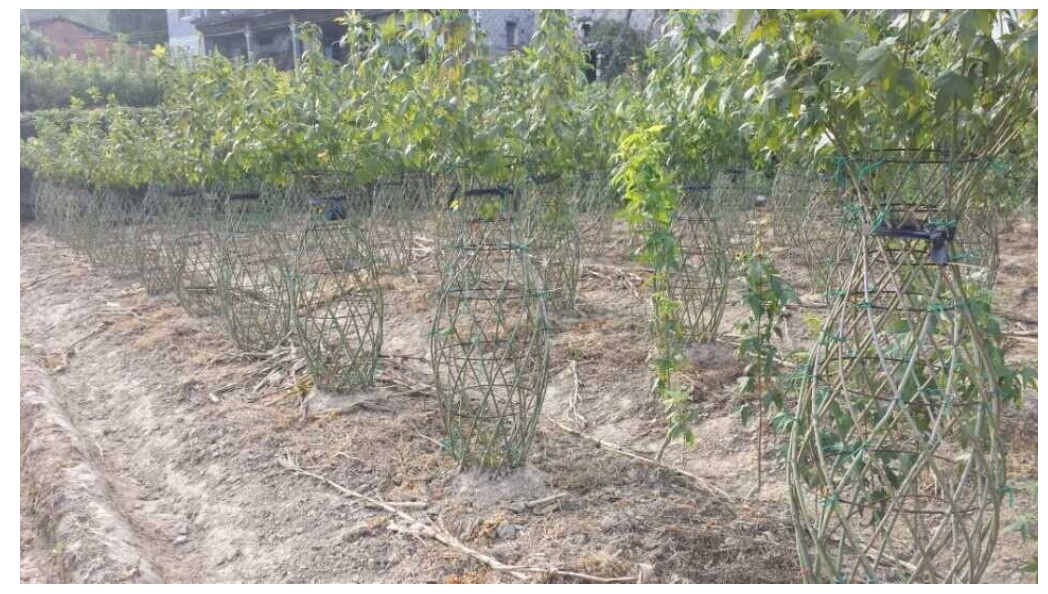

Figure 2. The Acer elegantulummaple braiding vase works

\section{Grafting of High Ornamental Species}

After the completion of the Acer elegantulum vase skeleton shape, different plants branches intertwined in together, the cross posted by dots will due to crush and healing together. After 2-3 years of cultivation, Acer elegantulum vase skeleton basically stable and molding. In the vase or other parts according to the requirement of the design, by means of grafting technique, give full play to the Maple Garden variety mix of ornamental, such as maple feathers and fountains, and 
other varieties with drooping characteristics, gold leaf of Acer palmatum, red maple, Jingui with streight shapes, or according to the needs of different color choice ornamental cultivars, and create a rich and colorful Acer elegantulum modeling works.

Grafting Season. The season of grafting is decided mainly based on its biological habits, and generally choose autumn or early spring dormancy for grafting. Special varieties can also grafted during the growth season of May to August.

Selection of Grafting Position. According to the design of the vase, it can be directly grafted on the vase neck edge some beautiful maple branches; it can also in bottle choice erect growth to the thick branches weave, formed the bottle upright to a combination of "branches", then grafting the plants according to the requirement of art, ornamental, select the appropriate number of branches. According to the shape of a vase need often dozens of parts were grafted to form well-proportioned tree.

Plants Management after Grafting. On the vase after grafting, the management technology and general management of ornamental varieties was similar to the grafted seedlings. The most fundamental difference is vase arbitrary a graft point is security vase ornamental indispensable place. Therefore, once found a graft failure and need according to the season in the shortest period of time given patch, to compensate for the missing.

\section{Daily Nurse of the Vase Shaped Maple}

Modelling Acer elegantulum maintenance management level directly affects the shape of the ornamental effect. One plant death will seriously affect the vase ornamental effect, so in carefully the strengthening of water, fertilizer, temperature conventional management basis, we also need to strengthen the morphology and maintenance management.

The Management of Pruning. Shape vase pruning maintenance management includes two aspects: one is the management of vase bottle Acer elegantulum seedlings to keep the vase clean and refreshing, including the Acer elegantulum root initiation branch pruning, bottle stems germination branches pruning; the second is mouth trimming management, the vase remained in the steady state of the design shape, avoid the destroy of the original shape of art attitude because of the growth of the plant, including thining out the graft union and above of the Acer elegantulum and pruning the shoots of grafted varieties.

Untie the Vase and Remove the Framework. Along with the growth of Acer elegantulum cross branches, the crossover node will squeeze the healing, and original cross point of binding material should be timely lifted to avoid the embedded tree and injured. Modeling in the vase body placed in the wire or bamboo sheet frame, with the fixed vase shaped the growth of seedlings should be promptly cut off. The vase is a more natural appearance, but also easy to future sales lifter, transportation $[\mathrm{J}]$.

The Acer elegantulum is rich in resources, high seeding efficiency, fast growth speed, flexibility good features, ease of preparation modeling. Its affinity with Jinye Acer palmatum, red maple, maple feathers and fountains, and ornamental high value horticultural varieties is strong, and easy to graft survival. The Acer elegantulum as plant (plant sculpture) modeling of plant material, the shape of the vase, style, screens and other various forms, and on the basis of the grafted high ornamental value of feather maple, red maple, fountains and other varieties, and finally the formation of two kinds of plants and the above combination of plant modeling products, greatly improves the ornamental value, meet the urban greening, green courtyard viewing needs, and also greatly improve the seedling production economic benefits.

\section{Acknowledgements}

[Supported by National spark plan project(2015G A701016); National spark plan project(2015GA701004); The major projects of agriculture and social development of Ningbo (2014C11002); Agricultural Science and Technology Achievements Transformation Funds Project (2014GB2C220150). 


\section{References}

[1] ZHU ZY. 2006. Modeling technology of garden plants [M]. Beijing: China Forestry Publishing House.

[2] HAN LW, ZHU ZY. Techniques of garden plants[M]. Beijing: Science press. 